\title{
ОПТИМИЗАЦИЯ СТРУКТУРЫ МОНИТОРИНГОВЫХ СЕТЕЙ НАБЛЮДЕНИЙ ЗА СОСТОЯНИЕМ ОЧИСТНЫХ СООРУЖЕНИЙ
}

\author{
В. Е. Левкевич 1 , В. А. Лосицкий²
}

${ }^{1}$ Д. т. н., профрессор, профрессор кафедры «Водоснабжение и водоотведение» Белорусского национального технического университета, Минск, Беларусь, e-mail: eco2014@tut.by

2 Магистр технических наук, старший преподаватель кафедры «Строительство и эксплуатация зданий и сооружений» Филиала БНТУ МИПКиПК; аспирант кафедры «Водоснабжение и водоотведение» БНТУ, Минск, Беларусь, е-mail: losickiy1993@gmail.com

\begin{abstract}
Рефрерат
В настоящей статье рассмотрены некоторые методические подходы по оптимизации сетей наблюдений системы мониторинга конструкций очистных сооружений и структурированию различных данных, получаемых в результате наблюдений за состоянием элементов очистных сооружений сточных вод с целью принятия определенных управленческих решений, направленных на улучшение эксплуатации водохозяйственных объектов. Приведен критерий оптимизации сетей наблюдений. Показана возможность оценки экономической целесообразности создания системы мониторинга состояния конструкций очистных сооружений сточных вод.
\end{abstract}

Ключевые слова: очистные сооружения, мониторинг, сети наблюдения, оптимизация.

\section{OPTIMIZATION OF THE STRUCTURE OF MONITORING NETWORKS FOR OBSERVING THE STATE OF TREATMENT FACILITIES}

\section{Abstract}

\section{E. Levkevich, V.A. Losickiy}

This article discusses some methodological approaches to optimize the observation networks of the monitoring system for the structures of wastewater treatment plants and the structuring of various data obtained as a result of observing the state of the elements of wastewater treatment facilities in order to make certain management decisions aimed at improving the operation of water facilities. A criterion for optimizing observation networks is given. The possibility of assessing the economic feasibility of creating a system for monitoring the state of structures of wastewater treatment facilities is shown.

Keywords: water treatment facilities, monitoring, surveillance networks, optimization

\section{Введение}

Как известно, в Беларуси во всех крупных городах, областных и районных центрах созданы и функционируют очистные сооружения [1].

Одним из наиболее распространенных методов очистки воды является биологическая очистка. В Республике Беларусь широкое распространение в качестве сооружений по биологической очистке получили биологические пруды и поля орошения и фильтрации. Применение этого метода с начала нашего века показало, что этот способ наиболее доступен, по сравнению с физико-химическим или биологическим в искусственных условиях и т. п. Простота эксплуатации, низкие эксплуатационные затраты, надежность сделали этот способ очистки сточных вод наиболее распространенным.

Большинство указанных объектов эксплуатируются значительный период отрезок времени, а с учетом того, что срок их эксплуатации в соответствии с классом капитальности сооружений не должен превышать пятидесятилетний период, оценка состояния объектов потенциальной опасности требует наличия объективной информации о техническом состоянии упомянутых сооружений и инженерных систем. Рассмотренная проблема является особенно актуальной с учетом возникновения чрезвычайных ситуаций на ОС со значительными ущербами природной среде и экономике регионов страны [2].

\section{Основная часть}

Наиболее распространенным и самым эфффективным методом оценки состояния сооружений инженерной защиты, систем водоснабжения и водоотведения, сооружений очистки сточных вод являются их натурные обследованиями как визуальными и инструментальными методами, так и современными методами с помощью аэрофотосъемки.

Проанализировав аварии на очистных сооружениях, произошедшие на территории Республики Беларусь за последние 10 лет, можно сделать вывод о том, что причины возникновения аварий могут быть самыми различными, связанными:

- с отключением электропитания;

- износом оборудования;
- метеоусловиями, осложняющими эксплуатацию (сильный мороз, осадки и наводнения);

- человеческим фактором (невнимание персонала, малая численность персонала, слабая техническая подготовка, теракты);

- отклонениями от нормального режима работы очистных сооружений (объем загрязненного материала больше запланированного, очистные сооружения не рассчитаны на уничтожение отдельных веществ и компонентов и т. п.);

- ошибками в проектировании и строительстве.

Ниже на рисунке 1 представлена диаграмма, иллюстрирующая соотношение причин возникновения аварий, характерных для Республики Беларусь.

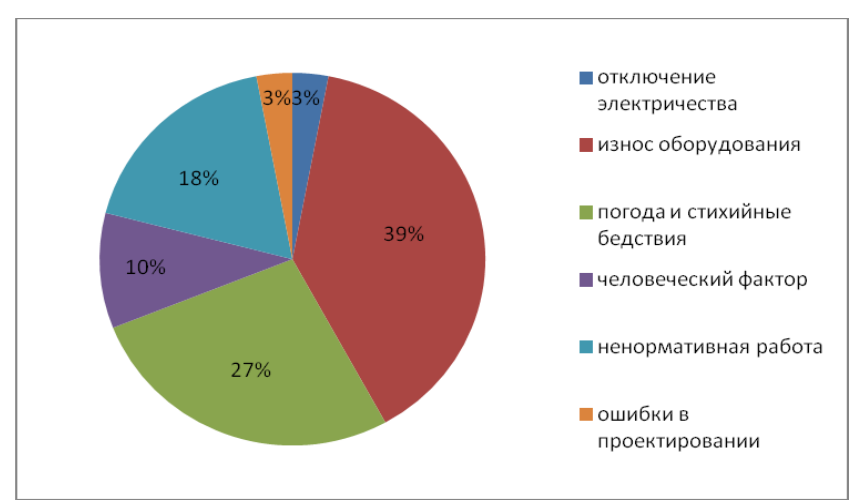

Рисунок 1 - Причины аварий на очистных сооружениях в Беларуси

Комплексное натурное обследование ряда очистных сооружений страны, проведенное в период исследований, показало, что состояние инженерных конструкций зачастую находиться в предаварийном состоянии.

Опасность нанесения экономического, экологического ущербов, а также опасность для жизни и здоровья людей, связанная с состоянием 
Вестник Брестского государственного технического университета. 2021

конструкций очистных сооружений на сегодняшний день в Республики Беларусь, диктует необходимость создания и внедрения на практике комплексной системы мониторига. Разрабатываемая экспериментальная система мониторинга конструкций очистных сооружений будет служить основой для принятия управленческих решений по предотвращению возникновения чрезвычайных ситуаций, а также минимизации ущерба в случае аварий.

Структура экспериментальной системы мониторинга состоит из 4 уровней (центральный, региональный, местный, локальный), тесно связанных между собой. Связь различных уровней предполагается осуществлять автоматически на основе использования универсальных (общепринятых, стандартных) форматов обмена данными, а также путем обмена стандартного комплекта карт и характеристик.

Основными потребителями мониторинговой информации будут являются: Министерство жилищнокоммунального хозяйства Республики Беларусь, Министерство по чрезвычайным ситуациям, Министерство природных ресурсов и охраны окружающей среды, Минздрав, Правительство, а при необходимости - Президент Республики Беларусь.

Субъектами мониторинга и прогнозирования возможных нештатных и аварийных ситуаций на очистных сооружениях являются МЖКХ, подразделения Министерства природных ресурсов и охраны окружающей среды Республики Беларусь (Минприроды) и МЧС Республики Беларусь.

Для информационного обеспечения мониторинга каждого конкретного сооружения по очистке сточных вод будет создана специализированная база данных (БД), куда будут заносится все основные характеристики состояния сооружений, по которым производится контроль, а также данные об их состоянии в реальном режиме времени. Она представляет собой массивы систематизированной информации, благодаря которой возможно комплексно оценить состояние того или иного сооружения, выполнить прогноз возможных деформаций необходимый для принятия правильного управленческого решения, необходимого для службы эксплуатации очистными сооружениями. База данных системы мониторинга может дополнительно включать в себя наземные измерения (обследования), онлайн-информацию белорусского центра метеорологии, статистику опроса, данные дистанционного зондирования земли и другую информацию.
Основными блоками являются: информационный блок, описание базы данных, алфавитный перечень сооружений, принадлежность к виду очистки сточных вод, территориальное расположение сооружения и другие.

Предлагаемая структура базы данных и алгоритм ее функционирования представлены ниже на рисунке 2.

Создание и внедрение системы мониторинга состояния конструкций очистных сооружений является достаточно дорогостоящим мероприятием. Для того, чтобы оценить, насколько эта система будет экономически обоснована и целесообразна, необходимо:

- определить оптимальное количество контрольных точек наблюдений;

- оценить и сравнить затраты на создание и эксплуатацию данной системы с затратами на восстановление сооружений после аварийных ситуаций.

Технически и экономически эта система будет выгодна тогда, когда стоимость ее внедрения и эксплуатации будет меньше, чем стоимость перечисленных выше мероприятий.

Оптимальное количество точек контроля (постов) системы мониторинга $(\mathrm{N}$ oпm) может определяется по критерию оптимальности следующего вида:

$$
\begin{aligned}
& \sum N \text { опт } \underset{\sum \Pi i \Rightarrow}{\Rightarrow}=>\quad \text { Пмин } \\
& \text { Пмин }
\end{aligned}
$$

где Пі - суммарные приведенные затраты на создание системы, руб. / год;

Пмин - приведенные затраты на создание 1 поста, руб. / год;

Nмин - количество минимальное точек контроля, шт.

Финансирование системы мониторинга должно осуществляться субъектами системы. Так как система мониторинга будет иметь национальный характер, то большая часть средств может быть выделена из государственного бюджета. Однако данная система также может быть частично финансирована из частного капитала лиц, заинтересованных в ее эксплуатации. Это возможно только при допуске конкретных частных инвесторов государственными органами.

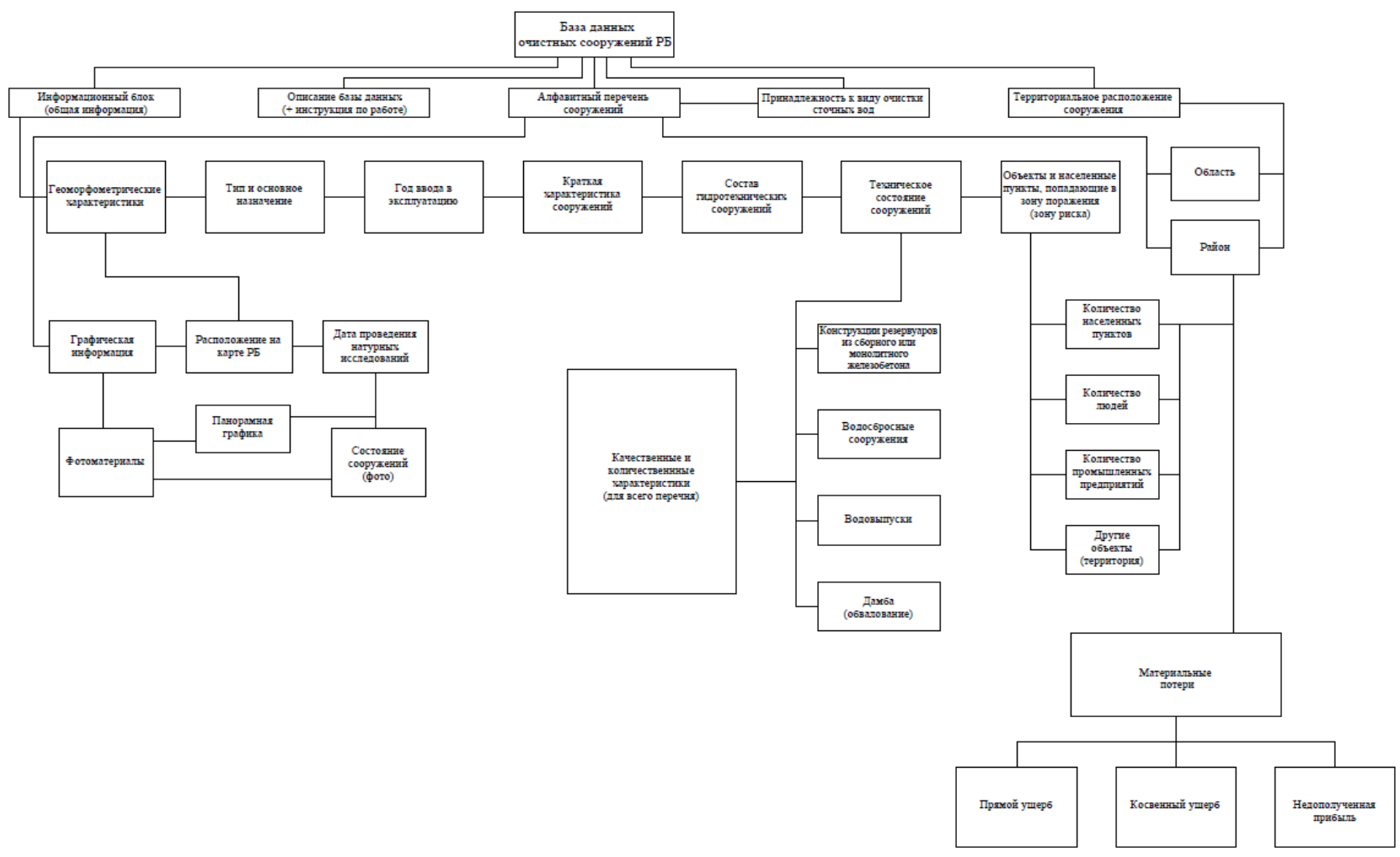

Рисунок 2 - Структура и алгоритм функционирования базы данных экспериментальной системы мониторинга 
Если возможно выделить величину годовых расходов на эксплуатацию системы мониторинга состояния конструкций очистных сооружений, то сравнение экономической эффективности сооружения следует выполнять путем сопоставления сумм приведенных затрат на внедрение и эксплуатацию системы мониторинга (2) и затрат на восстановление сооружений, вышедших из строя в течение года плюс затрат на борьбу с ущербом (экономическим, социальным, природным), вызванным аварийной ситуацией (3):

$$
\Pi i=M i+K i \cdot E H
$$

где Пі - приведенные затраты, руб. / год;

Mi - годовые эксплуатационные расходы, руб./год;

$E_{H}$ - нормативный коэфффициент эффективности капитальных вложений $(0,1 \ldots 0,18)$;

$K i$ - капитальные вложения, руб. / год.

$$
3 i=P i+Y i,
$$

где $3 i$ - затраты из-за аварийных ситуаций, руб./год;

$\mathrm{Pi}$ - затраты на восстановление сооружений, вышедших из строя вследствие аварий, руб. / год;

$Y i$ - затраты на борьбу с ущербом, вызванным авариями.

При соблюдении условия Пi < Зі, принимается решение о том, что создание и последующая эксплуатация системы мониторинга является экономически эффективной и целесообразной.

\section{Заключение}

Следует сделать вывод, что на сегодняшний момент реально существует опасность возникновения риск-ситуаций на очистных сооружениях Республики Беларусь. Полноценный контроль за состоянием сооружений, особенно местных и локальных, практически отсутствует. Одним из потенциальных подходов для решения проблемы контроля может явиться комплексная система мониторинга состояния очистных сооружений. Для реализации этой задачи на каждом объекте следует определять минимальное число точек контроля для чего разработан алгоритм и структура информационного обеспечения такой системы. Реализация системы мониторинга очистных сооружений должна выполняться поэтапно с учетом специфики и масштабов объектов и конструктивных особенностей.

\section{Список цитированных источников}

1. Левкевич В. Е. Экологический риск - закономерности развития, прогноз и мониторинг / В. Е. Левкевич. - Минск : ИООО «Право и экономика», 2004. - 152 с.

2. Информационный сайт [Электронный ресурс] / Очистка сточных вод в биологических прудах в условиях Йемена - Москва, 1999. Режим доступа: http://www.dissercat.com/ - Дата доступа: 19.11.2016.

3. Мониторинг и прогнозирование чрезвычайных ситуаций. Общие положения. Порядок функционирования системы мониторинга и прогнозирования чрезвычайных ситуаций: ТКП 304-2011. Введен 08.04.2011. - Минск : Министерство по чрезвычайным ситуациям Республики Беларусь, 2011.

4. Ляпичев Ю. П. Гидрологическая и техническая безопасность гидросооружений / Ю. П. Ляпичев. - М.: РУДН, 2008. - 222 с.

5. Информационный сайт [Электронный ресурс] / Геоинформационные системы - Минск, 2015. - Режим доступа: http://www.bseu.by/it/GIS/default.htm - Дата доступа: 18.09.2017.

\section{References}

1. Levkevich V. E. Ekologicheskij risk - zakonomernosti razvitiya, prognoz i monitoring / V. E. Levkevich. - Minsk : 1000 «Pravo i ekonomika», 2004. - $152 \mathrm{~s}$.

2. Informacionnyj sajt [Elektronnyj resurs] / Ochistka stochnyh vod v biologicheskih prudah $\mathrm{v}$ usloviyah Jemena - Moskva, 1999. Rezhim dostupa: http://www.dissercat.com/ - Data dostupa: 19.11.2016.

3. Monitoring i prognozirovanie chrezvychajnyh situacij. Obshchie polozheniya. Poryadok funkcionirovaniya sistemy monitoringa i prognozirovaniya chrezvychajnyh situacij: TKP 304-2011. - Vveden 08.04.2011. - Minsk: Ministerstvo po chrezvychajnym situaciyam Respubliki Belarus', 2011.

4. Lyapichev YU. P. Gidrologicheskaya i tekhnicheskaya bezopasnost' gidrosooruzhenij / YU. P. Lyapichev. - M.: RUDN, 2008. - 222 c.

5. Informacionnyj sait [Elektronnyj resurs] / Geoinformacionnye sistemy - Minsk, 2015. - Rezhim dostupa: http://www.bseu.by/it/GIS/default.htm - Data dostupa: 18.09.2017.

Материал поступил в редакцию 24.05.2021 